\title{
Planar Dual-Band Electrically Small Antenna Based on Double-Negative Metamaterials
}

\author{
Cheng Zhou, Guangming Wang, Yu Xiao \\ Laboratory of Microwave Technology and Application, Air and Missile Defense College, Air Force Engineering \\ University, Xi'an, China \\ Email: zcheng mic@163.com
}

Received December 2014

Copyright @ 2015 by authors and Scientific Research Publishing Inc.

This work is licensed under the Creative Commons Attribution International License (CC BY).

http://creativecommons.org/licenses/by/4.0/

c) (i) Open Access

\begin{abstract}
A coaxially fed dual-band electrically small antenna based on double-negative metamaterials is presented in this letter. The antenna consists of a microstrip patch antenna as driven element and a double-negative metamaterials shell as parasitic element. Nearly complete matching of the entire system to a $50 \Omega$ source without any matching network is achieved at $299 \mathrm{MHz}$ and $837 \mathrm{MHz}$, with $\mathrm{ka}=0.444$ and 1.242 respectively. Measured performance agrees with simulations, and the proposed antenna has considerable radiation efficiency and is suitably employed for VHF and UHF applications.
\end{abstract}

\section{Keywords}

Electrically Small, Planar, Efficiency, Quality

\section{Introduction}

Electrically small antennas (ESAs) have drawn much attention and have been extensively studied in a long decades for a variety of wireless applications. Due to its compact dimension, an ESA always exhibits high impedance mismatch, high quality factor $(Q)$; and, therefore, low radiation efficiency (RE) and overall efficiency (OE) and narrow fractional bandwidth (FBW). For an electric or magnetic small antenna, there is a fundamental lower bound for the quality factor that is determined as Chu-limiation concerning the antenna's physical size and operating wavelength [1]. The famous formula $Q \approx 1 /(k a)^{3}+1 /(k a)$ (a being the radius of the smallest sphere that completely encloses the antenna at the operational frequency, and $k$ is the free space wave number) indicates that a smaller $k a$ leads to a lager $Q$, resulting in narrower bandwidth and lower radiation efficiency. Many communities have devoted themselves to develop the theory of ESA [2]-[5]. A remarkable viewpoint is that metamaterial-inspired Near-Field Resonant Parasitic (NFRP) electrically small antenna can achieve nearly com- 
plete matching of the entire system to a $50 \Omega$ source without any external matching network and to yield high radiation efficiencies [6].

Aim to realize the metamaterial-inspired NFRP electrically small antennas, many designs have been reported in [7]-[23]. The most famous one called "EZ" small antenna [9] [12] [16] [17] generally employs electric monopole or semi loop as driven element and epsilon negative (ENG) metamaterial or capacitively loaded loop (CLL) as parasitic element, but it always seem to be too cumbersome to assemble on aircraft and other unmanned vehicle. Others such as egyptian axe dipole antenna [22] [23], stub antenna, canopy antenna [14], multifunctional and active NFRP antenna [20] [24] are also attracting many interests. Though there have been many structures in designing NFRP antenna, the common point can be depict as that a high radiated efficiency was possible by compensating the large capacitive (inductive) reactance by the inductive (capacitive) reactance of a double-negative (DNG) shell surrounding the electrically small driven element. The inductive (capacitive) impedance offered by the DNG shell was caused due to a change in sign of the reactive part of the complex power radiated by the driven element in an infinite DNG medium. Furthermore, compared to 3D version, the planar printed NFRP ESA has attracted much more attention owing to the advantages such as low profile, high efficiency, ease of fabrication and installation, etc. [21] [22].

This paper proposed a dual mode planar printed NFRP ESA based on DNG metamaterials. By adjusting the capacitor and inductor values, nearly complete match to the $50 \Omega$ sources in very close proximity to $300 \mathrm{MHz}$ and $840 \mathrm{MHz}$ was achieved. We note that in this paper, the criterion of an ESA is that $k a \leq 1$ [2]. And the numerical simulations and their optimizations were carried out using the frequency domain ANSYS/ANSOFT HFSS.

\section{Design of Electrically Small Antenna}

In many of the reported designs, the fundamental resonance of an NFRP antenna can be either electric or magnetic. An electric resonance generates an electric dipole mode, and a magnetic resonance generates a loop mode. In planar version, the most adopted driven element was often selected to be electric dipole because it would bring the NFRP antenna a broad bandwidth characteristic [22], but it has a relative large back lobe and needs some special technique for feeding, thus restricts ESA's application.

Both of 3D perspective and plane view of the proposed planar electrically small antenna is shown in Figure $\mathbf{1}$. The new configuration consists of two stacked dielectric substrate isolated by air. There is a rectangle patch on the top of the first substrate with $\varepsilon_{r 1}=2.65, h_{1}=3 \mathrm{~mm}$ and a rectangle patch etched with interdigital capacitor on the top of the second substrate with $\varepsilon_{r 2}=2.65, h_{2}=0.5 \mathrm{~mm}$, connecting to the ground though two metallic cylinders. In our designs, the planar microstrip patch antenna (MPA) was chose as the driven element. This is mainly due to the advantage of its integrated ground plane and easily to be fixed on other platforms.

According to the near-field resonant parasitic viewpoint, patch 1 is for driven element [see Figure 1(b)], and is immediately fed by $50 \Omega$ coaxial coble; the combination of patch 2 together with the two metallic cylinders [see Figure 1(c)] can be seen as a double-negative shell enclosing on the hemisphere of patch 1. Actually, it can be drawn in Figure 2 that the equivalent model of the whole antenna system. In Figure 2, represents the inherent

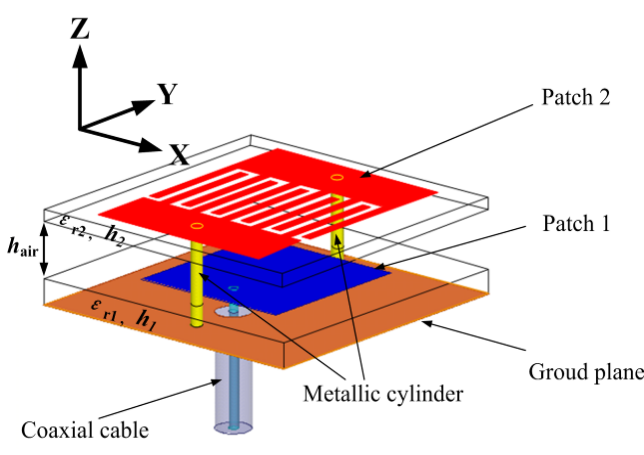

(a)

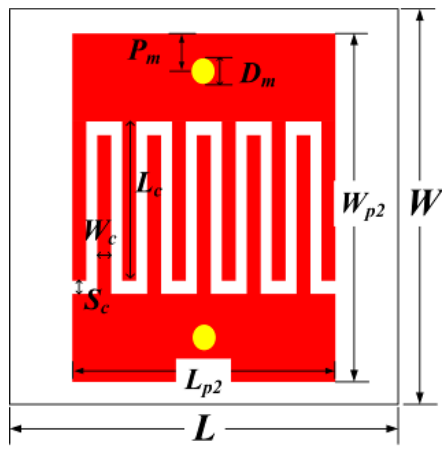

(b)

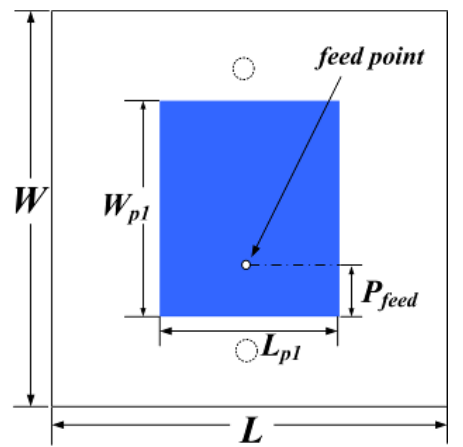

(c)

Figure 1. Structure of the proposed electrically small antenna with (a) 3D view (b) upper layer and (c) nether layer. All dimensions are in mm: $L=100, W=100, h_{\text {air }}=3.5 \mathrm{~mm}, \mathrm{~L}_{\mathrm{p} 1}=62, \mathrm{~W}_{\mathrm{p} 1}=65.4, \mathrm{P}_{\text {feed }}=17, \mathrm{~L}_{\mathrm{p} 1}=58.4, \mathrm{~W}_{\mathrm{p} 1}=82, \mathrm{P}_{\mathrm{m}}=4, \mathrm{D}_{\mathrm{m}}=$ $1.3, \mathrm{Lc}=20.6, \mathrm{Wc}=0.8, \mathrm{Sc}=0.8$. 
capacitance of patch antenna, and represents the series capacitance and shunt inductance of the DNG metamaterials, and depicts the coupled capacitance between the patch and DNG metamaterials. Thus, the resonant frequency of the circuit model is approximately

$$
f_{\text {res }} \approx \frac{1}{2 \pi} \sqrt{\frac{2\left(C_{c}+C_{p}\right)}{L_{p} C_{c} C_{p}+L_{p} C_{a}\left(C_{c}+C_{p}\right)}}
$$

The HFSS-predicted performance characteristics of this electrically small antenna are given in Figure $\mathbf{3}$ and Figure 4. For comparison, the corresponding results for the same sized microstrip patch antenna (MPA) shown in Figure 1(b) are also given.

As is shown in Figure 3(a), the fundamental resonance frequency of this MPA appears at $1316 \mathrm{MHz}$, with the input impedance value $Z_{i n}=72.15+j 4.3 \Omega$. This is the well known half wavelength $\left(\lambda_{0} / 2\right)$ resonance frequency. Not similar to Figure 4(a), one can see from Figure 3(b) that besides the RF frequency $1420 \mathrm{MHz}$ with the impedance value $Z_{i n 3}=514.4-j 37.2 \Omega$; there are other two resonance modes inspired at $837 \mathrm{MHz}$ and 299

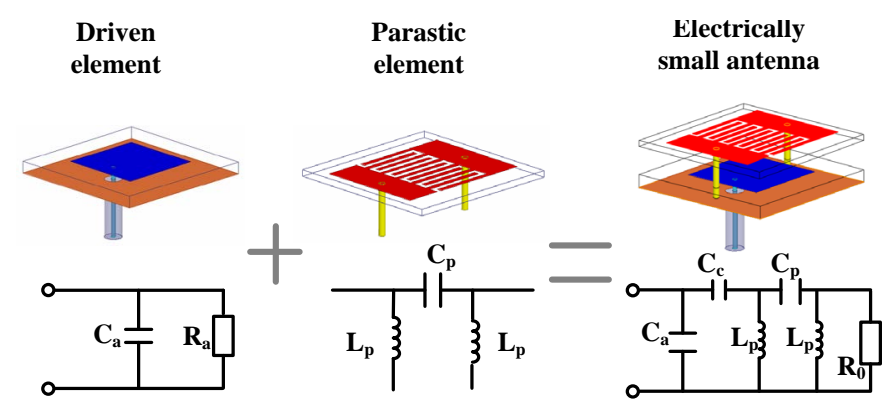

Figure 2. Lumped element circuit for the proposed electrically small antenna.

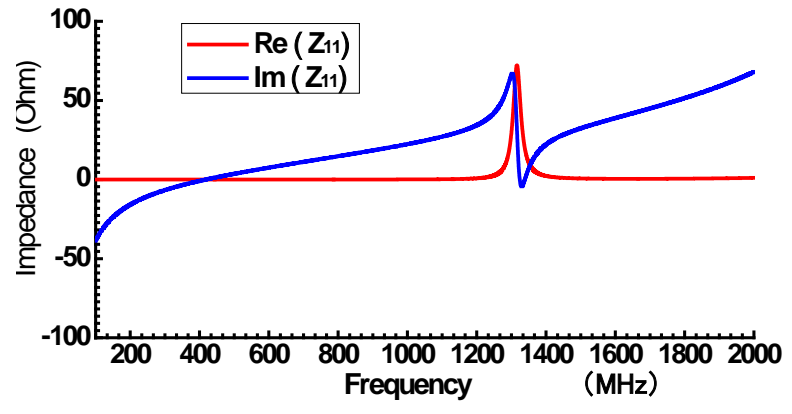

(a)

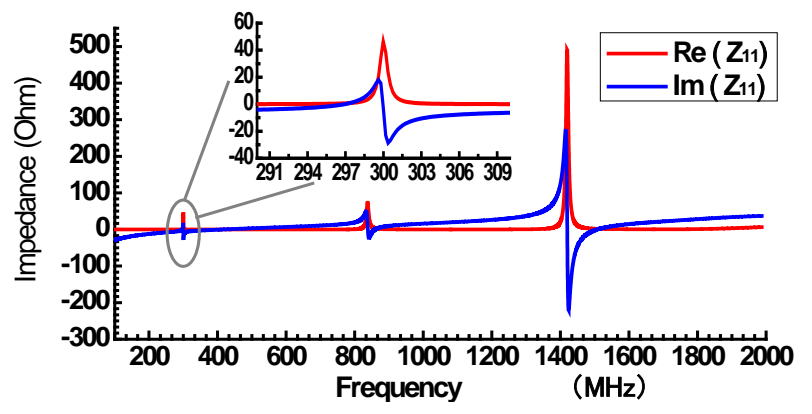

(b)

Figure 3. HFSS-predicted input impedance values versus frequency for (a) conventional MPA; (b) Proposed ESA based on DNG metamaterial.

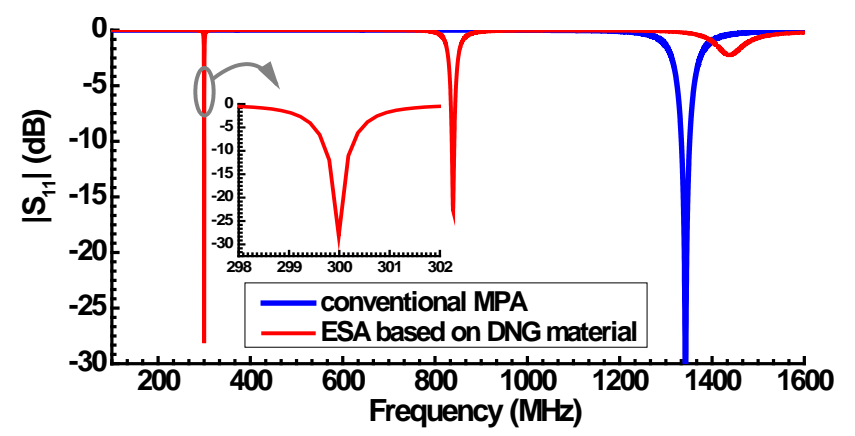

Figure 4. HFSS-predicted $\left|S_{11}\right|$ values versus frequency for conventional MPA and proposed ESA based on DNG metamaterial. 
MHz, with their impedance value $Z_{i n 2}=72.5+j 20.9$ and $Z_{i n 1}=43.7+j 8.3$ respectively. The HFSS-predicted reflection coefficients of the proposed ESA were shown in Figure 4 along with that of the conventional MPA. From Figure 4 it is clear that the proposed ESA based on DNG metamaterial has three resonance frequencies, a well impedance matching is obtained at the VHF and UHF.

For studying the radiate mechanism of the proposed ESA, the 3D polar radiation patterns operating at 299 MHz, $837 \mathrm{MHz}$, and $1420 \mathrm{MHz}$ were shown in Figure 5. At $299 \mathrm{MHz}$, the maximum radiate direction is at $\mathrm{XOZ}$ plane, this can be seen as end-fire omnidirectional antenna; at $837 \mathrm{MHz}$, the maximum radiate direction is at XOY plane, this can be seen as broadside omnidirectional antenna; at $1420 \mathrm{MHz}$, the maximum radiate direction is at $+Z$ direction, this can be seen as half wavelength $\left(\lambda_{0} / 2\right)$ radiation model, in other words, a conventional patch antenna.

Since the third resonance frequency showing in Figure $\mathbf{3}$ and Figure $\mathbf{4}$ was not a good impedance matching, we prefer to research the first and second resonance frequency which belongs to VHF and UHF respectively. Figure 6 and Figure 7 depict the electric field distributions predicted by HFSS both on the upper and nether plane, and the black arrow expresses the direction of induced current. In Figure 6, the electrical field mainly concentrates at the centre on the upper layer, this demonstrates that the interdigital capacitor is the main contributor for electromagnetic wave radiating. The current direction on the two layers indicates that this radiation maybe a linearly polarized model along $X$ direction. In Figure 7, the electrical field concentrates both on the edge of the upper patch and the nether patch. The current distribution is symmetrical with respect to YOZ plane on the upper patch central symmetrical on the nether patch. This makes the antenna like a zeroth-order resonant cavity and radiates a linearly polarized model along $\mathrm{Z}$ direction.

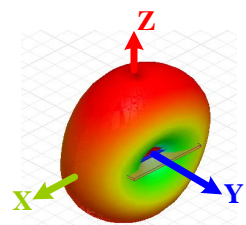

(a)

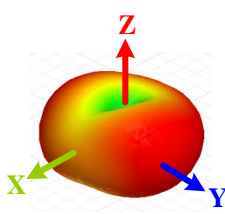

(b)

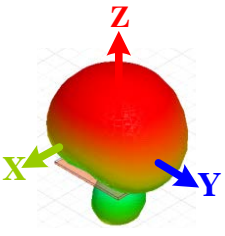

(c)

Figure 5. HFSS-predicted 3D polar radiation pattern of proposed ESA operating at (a) $299 \mathrm{MHz}$, (b) $837 \mathrm{MHz}$, (c) $1420 \mathrm{MHz}$.
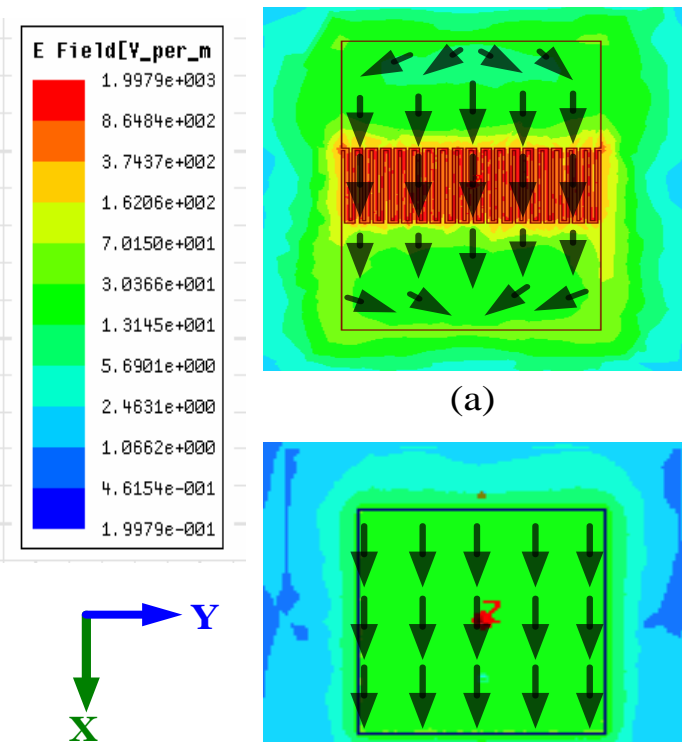

(a)

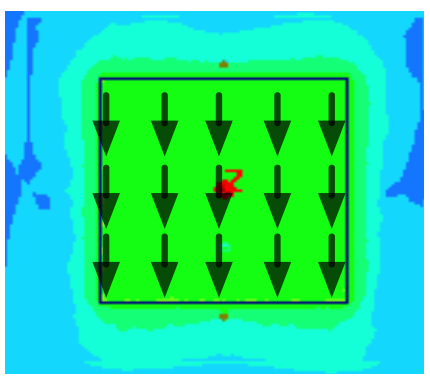

(b)

Figure 6. HFSS-predicted E-field distribution on (a) the upper layer and (b) nether layer of the proposed ESA operating at 299.6 MHz. 


\section{Experimental Results of the Proposed Electrically Small Antenna}

Figure 8 shows the prototype of the fabricated electrically small antenna. Both driven and parasitic elements were printed on the $100 \times 100 \mathrm{~mm}^{2} \mathrm{~F} 4 \mathrm{~B}$ substrate $\left(\varepsilon_{r}=2.65, \tan \sigma=0.001\right)$ specified by the design illustrated in Figure 1. It is a double layer stacked antenna separated by air and fed by a coaxial cable with characteristic impedance equal to $50 \Omega$ on the back ground. Then it was connected to the vector network analyzer (VNA) cable and measured its network characteristics.

The measured reflection coefficient of the proposed antenna is plotted in Figure 9 along with that calculated via full-wave simulation by the HFSS. The measured resonant frequency is about $1 \%$ shifts higher than the simulated one, which can be contributed to fabrication process and dielectric constant tolerance in a frequency regime. The $3 \mathrm{~dB}$ fractional bandwidth $\left(\mathrm{FBW}_{3 \mathrm{~dB}}\right)$ is $1.5 \mathrm{MHz}$ extended from $301.59 \mathrm{MHz}$ to $303.20 \mathrm{MHz}, 19$ $\mathrm{MHz}$ extended from 832.26 MHz to 851.26 MHz, corresponding to fractional bandwidth of $0.5 \%$ and $2.3 \%$, respectively. The narrow bandwidth demonstrated that the high quality factor (Q) and strong resonance characteristic of the electrically small antenna. Enhanced bandwidth would be obtained by introducing a NIC circuit based on non-Foster element.

The numerical and experimental radiation patterns of the proposed dual-band antenna operating at $299 \mathrm{MHz}$ and $837 \mathrm{MHz}$ are shown in Figure 10. At $299 \mathrm{MHz}$, in E-plane [seeing Figure 10(a)] the maximum lies on +Z
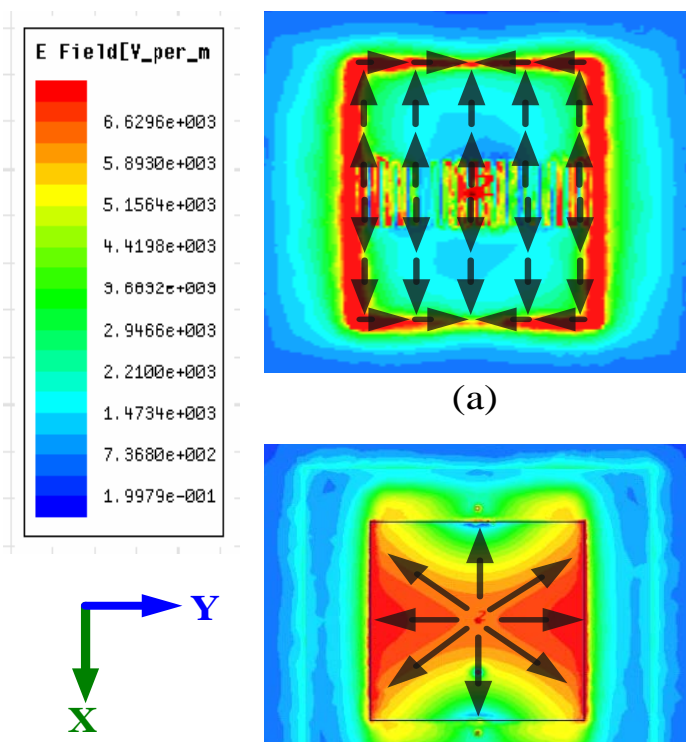

(a)

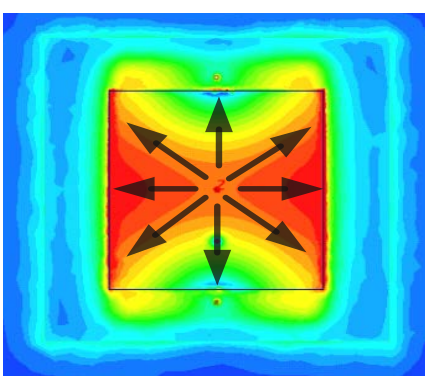

(b)

Figure 7. HFSS-predicted E-field distribution on (a) the upper layer and (b) nether layer of the proposed ESA operating at $299.6 \mathrm{MHz}$.

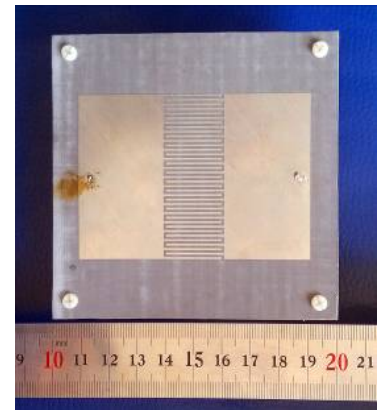

(a)

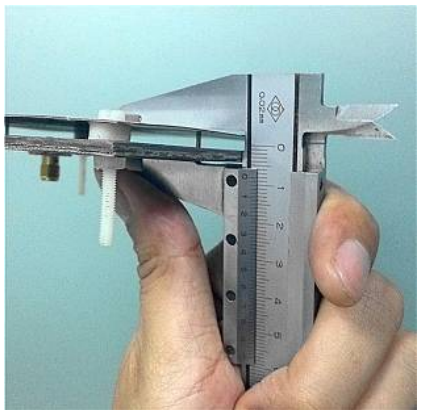

(b)

Figure 8. Photogragh of the proposed antenna. (a) Top view; (b) Side view. 


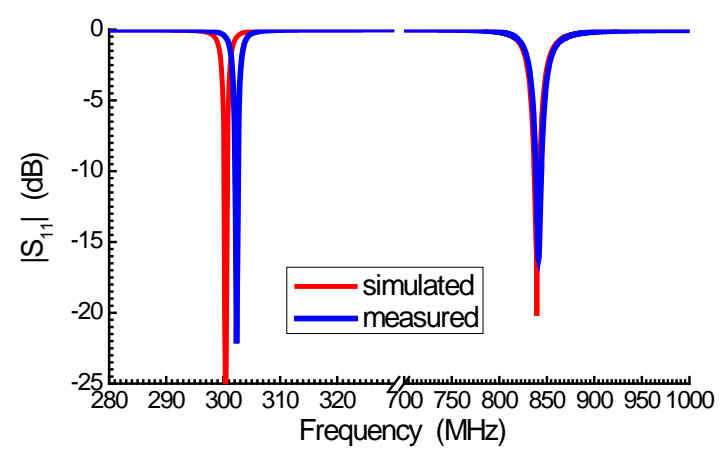

Figure 9. Measured and simulated reflection coefficient of the proposed dual-band antenna.

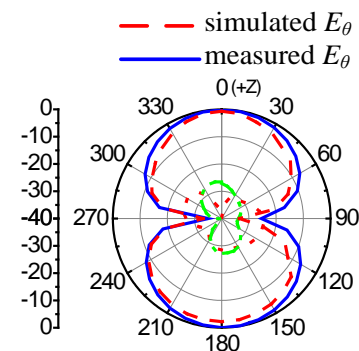

(a)

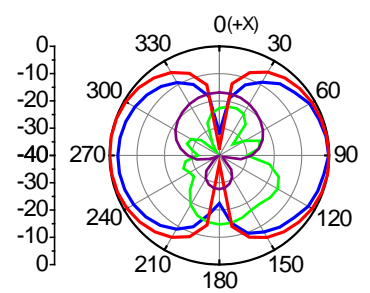

(c)

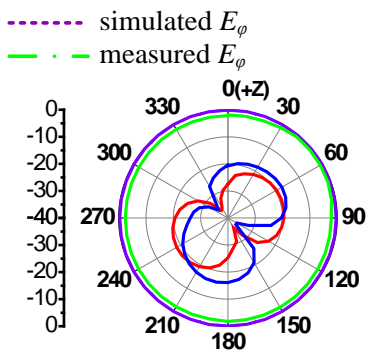

(b)

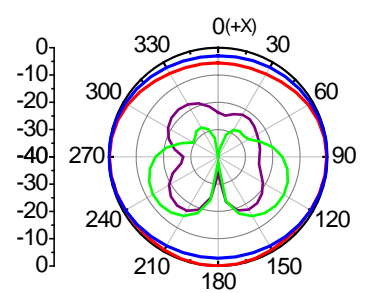

(d)

Figure 10. The simulated and measured radiation patterns at $299 \mathrm{MHz}$ in (a) YZ plane, (b) XZ plane; at $837 \mathrm{MHz}$ in (c) YZ plane, (d) XY plane.

direction $\left(\theta=0^{\circ}\right)$ and in H-plane [seeing Figure 10(b)] the proposed antenna has an omnidirectional radiation characteristic. At $837 \mathrm{MHz}$, in E-plane [seeing Figure 10(c)] the maximum lies on $+\mathrm{Y}$ direction $\left(\theta=90^{\circ}\right)$ and in H-plane [seeing Figure 10(d)] the proposed antenna has an approximately omnidirectional radiation characteristic. Since the antenna has a none-damaged ground plane, the back lobe can be reasonably decreased when it is fixed on a sufficiently large metal platform.

The measured antenna efficiency and peak gain are presented in Figure 11. When operating at VHF, the efficiency of the proposed antenna is higher than $70 \%$ over the 3-dB bandwidth spectrum with a peak value of $75 \%$; when operating at UHF, the efficiency of the proposed antenna is higher than $95 \%$ over the 3-dB bandwidth spectrum with a peak value of $98 \%$. The measured peak gain is $0.2 \mathrm{dBi}$ and $2.8 \mathrm{dBi}$ at $299 \mathrm{MHz}$ and $837 \mathrm{MHz}$ respectively.

\section{Conclusion}

A dual-band electrically small antenna based on double-negative (DNG) metamaterials is proposed and experimentally studied in this communication. The new structure consists of a microstrip patch antenna as driven element and a double-negative shell as parasitic element. Nearly complete matching with no external matching circuit was achieved at $299 \mathrm{MHz}$ and $837 \mathrm{MHz}$, which belongs to VHF and UHF spectrum respectively. Even though the fractional bandwidth is less than those which are already assembled in the commercial products, the 


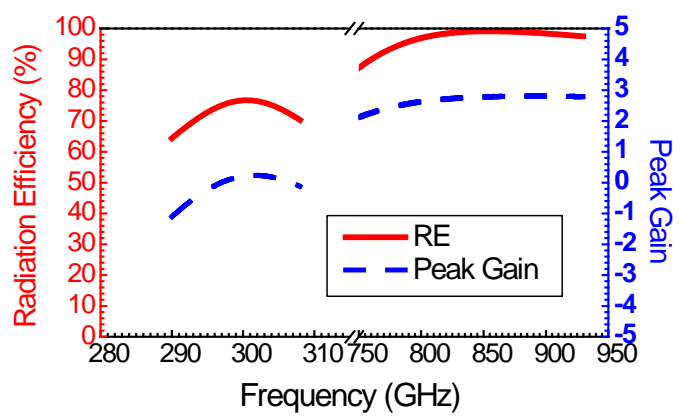

Figure 11. Measured radiation efficiency and peak gain of the proposed antenna.

compact size and the none-damaged ground configuration of the proposed antenna still demonstrate the potential of applying the antenna to the wireless communication.

\section{References}

[1] Chu, L.J. (1948) Physical Limitations of Omnidirectional Antennas. J. Appl. Phys, 19, 1163-1175. http://dx.doi.org/10.1063/1.1715038

[2] Wheeler, H.A. (1947) Fundamental Limitations of Small Antennas. IRE Proc., 35, 1479-1484.

[3] Wheeler, H.A. (1959) The Radiansphere Around a Small Antenna. IRE Proc., 47, 1325-1331.

[4] Wheeler, H.A. (1975) Small Antennas. IEEE. Trans. Antennas Propag, AP-23.

[5] Best, S.R. (2005) Low Q Electrically Small Linear and Elliptical Polarized Spherical Dipole Antennas. IEEE. Trans. Antennas Propag., 53, 1047-1053. http://dx.doi.org/10.1109/TAP.2004.842600

[6] Ziolkowski, R.W., Jin, P. and Lin, C.-C. (2011) Metamaterial-Inspired Engineering of Antennas. Proc. IEEE, 99, 1720-1731. http://dx.doi.org/10.1109/JPROC.2010.2091610

[7] Erentok, A. and Ziolkowski, R.W. (2007) An Efficient Metamaterial-inspired Electrically-Small Antenna. Microw. Opt. Tech. Lett., 49, 1287-1290.

[8] Erentok, A. and Ziolkowski, R.W. (2007) Two-Dimensional Efficient Metamaterial-Inspired Electrically-Small Antenna. Microw. Opt. Tech. Lett., 49, 1669-1673.

[9] Erentok, A. and Ziolkowski, R.W. (2008) Metamaterial-Inspired Efficient Electrically Small Antennas. IEEE. Trans. Antennas Propag., 56, 691-707. http://dx.doi.org/10.1109/TAP.2008.916949

[10] Ziolkowski, R.W. (2008) Efficient Electrically Small Antenna Facilitated by a Near-Field Resonant Parasitic. IEEE Antennas Wireless Propag. Lett., 7, 580-583. http://dx.doi.org/10.1109/LAWP.2008.2000558

[11] Ziolkowski, R.W. (2008) An Efficient, Electrically Small Antenna Designed for VHF and UHF Applications. IEEE Antennas Wireless Propag. Lett., 7, 217-220. http://dx.doi.org/10.1109/LAWP.2008.921635

[12] Ziolkowski, R.W., Lin, C.-C., Nielsen, J.A., Tanielian, M.H. and Holloway, C.L. (2009) Design and Experimental Verification of a 3D Magnetic EZ Antenna at $300 \mathrm{MHz}$. IEEE Antennas Wireless Propag. Lett., 8, 989-993. http://dx.doi.org/10.1109/LAWP.2009.2029708

[13] Ziolkowski, R.W., Jin, P., Nielsen, J.A., Tanielian, M.H. and Holloway, C.L. (2009) Experimental Verification of Z Antennas at UHF Frequencies. IEEE Antennas Wireless Propag. Lett., 8, 1329-1333. http://dx.doi.org/10.1109/LAWP.2009.2038180

[14] Jin, P. and Ziolkowski, R.W. (2009) Low Q, Electrically Small, Efficient Near-Field esonant Parasitic Antennas. IEEE. Trans. Antennas Propag., 57, 2548-2563. http://dx.doi.org/10.1109/TAP.2009.2027162

[15] Jin, P. and Ziolkowski, R.W. (2010) Broadband, Efficient, Electrically Small Metamaterial-Inspired Antennas Facilitated by Active Near-Field Resonant Parasitic Elements. IEEE. Trans. Antennas Propag., 58, 318-327. http://dx.doi.org/10.1109/TAP.2009.2037708

[16] Lin, C.-C., Ziolkowski, R.W., Nielsen, J.A., Tanielian, M.H. and Holloway, C.L. (2010) An Efficient, Low Profile, Electrically Small, Three-Dimensional, Very High Frequency Magnetic EZ Antenna. Appl. Phys. Lett., 96, Article ID: 104102. http://dx.doi.org/10.1063/1.3357430

[17] Lin, C.-C., Jin, P., Ziolkowski, R.W. (2011) Multi-Functional, Magnetically-Coupled, Electrically Small, Near-Field Resonant Parasitic Wire Antennas. IEEE. Trans. Antennas Propag., 59, 691-707.

[18] Jin, P. and Ziolkowski, R.W. (2011) Multi-Frequency, Linear and Circular Polarized, Metamaterial-Inspired, Near- 
Field Resonant Parasitic Antennas. IEEE. Trans. Antennas Propag., 59, 1446-1459.

[19] Tang, M.-C. and Ziolkowski, R.W. (2013) Efficient, High Directivity, Large Front-to-Back-Ratio, Electrically Small, Near-Field-Resonant-Parasitic Antenna. IEEE Access, 1, 16-28. http://dx.doi.org/10.1109/ACCESS.2013.2259134

[20] Zhu, N. and Ziolkowski, R.W. (2012) Broad-Bandwidth, Electrically Small Antenna Augmented With an Internal Non-Foster Element. IEEE Antennas Wireless Propag. Lett., 11, 1116-1120. http://dx.doi.org/10.1109/LAWP.2012.2219572

[21] Jin, P., Lin, C.-C. and Ziolkowski, R.W. (2012) Multifunctional, Electrically Small, Planar Near-Field Resonant Parasitic Antennas. IEEE Antennas Wireless Propag. Lett., 11, 200-204. http://dx.doi.org/10.1109/LAWP.2012.2187322

[22] Jin, P. and Ziolkowski, R.W. (2012) High-Directivity, Electrically Small, Low-Profile Near-Field Resonant Parasitic Antennas. IEEE Antennas Wireless Propag. Lett., 11, 305-309. http://dx.doi.org/10.1109/LAWP.2012.2190030

[23] Tang, M.-C., Zhu, N. and Ziolkowski, R.W. (2013) Augmenting a Modified Egyptian Axe Dipole Antenna With Non-Foster Elements to Enlarge Its Directivity Bandwidth. IEEE Antennas Wireless Propag. Lett., 12, 421-424. http://dx.doi.org/10.1109/LAWP.2013.2254103

[24] Zhu, N. and Ziolkowski, R.W. (2012) Design and Measurements of an Electrically Small, Broad Bandwidth, NonFoster Circuit-Augmented Protractor Antenna. Appl. Phys. Lett., 101, Article ID: 024107. http://dx.doi.org/10.1063/1.4736996 